\title{
Gambaran Fungsi Kognitif pada Lanjut Usia di Desa Sendangan Kecamatan Remboken
}

\author{
Nadia V. Roring ${ }^{1}$, Junita Maja Pertiwi ${ }^{2}$, Corry Novita Mahama ${ }^{3}$ \\ ${ }^{1}$ Program Studi Pendidikan Dokter Fakultas Kedokteran Univeristas Sam Ratulangi Manado \\ ${ }^{2}$ Bagian Neurologi Fakultas Kedokteran Univeristas Sam Ratulangi Manado \\ Email: nadia.roring@gmail.com
}

\begin{abstract}
Increased elderly in Indonesia grows in number and affects the health problems such as impaired cognitive function. Examination carried out by using Indonesian version Montreal Cognitive Assessment (MoCA-INA), Trail Making Test (TMT), and the Clock Drawing Test (CDT) are used to determine the cognitive function. This study was aimed to obtain the profile of cognitive function among the elderly at nursing home and outside of nursing home at Sendangan, Remboken. This was a descriptive study with a cross sectional design. The results showed that there were 59 people that met inculsion criteria. The InaMoCA examination showed that $94.9 \%$ of the elderly had a decline in cognitive function. Moreover, the TMT-A and TMT-B found that $100 \%$ of the elderly had impaired cognitive function. Meanwhile, the CDT found that $49.2 \%$ of the elderly had impaired cognitive function. In conclusion, the Ina-MoCA, TMT-A, TMT-B, and CDT indicated that the majority of the elderly at Sendangan, Remboken had impaired cognitive function.
\end{abstract}

Keywords: elderly, cognitive function, Ina MoCA, TMT-A, TMT-B, CDT

\begin{abstract}
Abstrak: Peningkatan lanjut usia di Indonesia semakin bertambah yang berdampak pada masalah kesehatan, salah satunya ialah gangguan fungsi kognitif. Pemeriksaan Montreal Cognitive Assesment versi Indonesia (INA-MoCA), Trail Making Test (TMT), dan Clock Drawing Test (CDT) dapat digunakan untuk medeteksi gangguan fungsi kognitif, Penelitian ini bertujuan untuk mengetahui gambaran fungsi kognitif pada lanjut usia di Panti Werdha dan luar Panti Werdha di Desa Sendangan Kecamatan Remboken. Jenis penelitian ialah deskriptif dengan desain potong lintang. Hasil penelitian mendapatkan 59 orang yang memenuhi kriteria penelitian. Pemeriksaan Ina-MoCA menunjukkan 94,9\% lanjut usia mengalami penurunan fungsi kognitif. Pada pemeriksaan TMT-A dan TMT-B didapatkan $100 \%$ lanjut usia terganggu. Pemeriksaan CDT mendapatkan 49,2\% lanjut usia terganggu. Simpulan penelitian ini ialah hasil pemeriksaan Ina-MoCA, TMT-A, TMT-B, dan CDT menunjukkan bahwa sebagian besar lansia di Desa Sendangan Kecamatan Remboken memiliki fungsi kognitif yang terganggu.
\end{abstract}

Kata kunci: lanjut usia, fungsi kognitif, Ina MoCA, TMT-A, TMT-B, CDT

\section{PENDAHULUAN}

Peningkatan lanjut usia (lansia) di Indonesia semakin bertambah banyak sehingga Indonesia termasuk salah satu negara dengan kelompok penduduk usia lanjut (aging population) yaitu penduduk yang berusia 60 tahun ke atas (penduduk lansia). Berdasarkan data proyeksi penduduk di tahun 2017 di perkirakan penduduk lansia di Indonesia terdapat 23,66 juta jiwa dan pada tahun 2020 diperkirakan menjadi 40,95 juta dan pada tahun 2035 akan menjadi 48,19 juta. ${ }^{1}$

Peningkatan penduduk lanjut usia dapat menyebabkan berbagai macam masalah yaitu, kesehatan, pendidikan, dan sosial. ${ }^{1}$ Hal ini dapat terjadi karena proses perubahan fisik-biologis, mental, atau 
psikososial. ${ }^{2}$ Dengan perubahan ini maka banyak lansia mengalami gangguan kognitif.

Gangguan kognitif dapat menyebabkan masalah dengan pikiran, komunikasi, pemahaman atau ingatan seseorang sehingga mengganggu aktivitas sehari-sehari. ${ }^{3}$ Pada lansia dengan gangguan kognitif dapat dilakukan pemeriksaan yang cepat dan praktis namun nilainya tinggi yaitu pemeriksaan Mini Mental State Examination (MMSE) atau dalam versi Indonesia Montreal Cognitive Asssement (InaMoCA $)^{2}$, Trail Making Test $A$ dan $B$ (TMT A \& B), dan Clock Drawing Test (CDT). ${ }^{4}$

Berdasarkan permasalahan yang telah dipaparkan maka peneliti tertarik untuk mengetahui gambaran fungsi kognitif pada lansia di Desa Sendangan Kecamatan Remboken.

\section{METODE PENELITIAN}

Penelitian ini dilaksanakan sejak bulan September-November 2019, yang bertempat di Desa Sendangan Kecamatan Remboken. Jenis penelitian ialah deskriptif dengan desain potong lintang. Responden penelitian ialah lansia yang berusia 60 tahun ke atas dan bersedia menjadi responden penelitian ini. Instrumen penelitian menggunakan Montreal Cognitive Assessment versi Indonesia (INA-MoCA), Trail Making Test (TMT), dan Clock Drawing Test (CDT).

Penelitian ini telah mendapat persetujuan dari Komisi Etik Penelitian Kesehatan RSUP Prof. Dr. R. D. Kandou Manado, dengan nomor keterangan layak etik yaitu No. 103/EC/KEPK-KANDOU/XII/2019.

\section{HASIL PENELITIAN}

Pada penelitian ini terdapat 59 lansia yang diikut sertakan sebagai responden penelitian, terdiri dari 11 laki-laki $(18,6 \%)$ dan 48 perempuan $(81,4 \%)$. Sebagian besar responden berusia $60-70$ tahun $(52,5 \%)$ dan tidak bekerja yaitu 48 responden $(81,4 \%)$. Berdasarkan pendidikan terakhir, didapatkan responden yang menjalani pendidikan terakhir di sekolah dasar yaitu 35 lansia $(59,3 \%)$. Berdasarkan riwayat penyakit hipertensi didapatkan 24 lansia (40,7\%) menyandang hipertensi dan berdasarkan riwayat penyakit diabetes melitus didapatkan 4 lansia $(6,8 \%)$ yang menyandang diabetes melitus.

Pada pemeriksaan dengan menggunakan Ina-MocA didapatkan 3 responden (5\%) dengan fungsi kognitif normal dan 56 orang $(95 \%)$ dengan penurunan fungsi kognitif. Pada pemeriksaan TMT-A dan TMT-B didapatkan 59 responden (100\%) terganggu sedangkan pada pemeriksaan CDT terdapat 29 responden (49\%) normal dan 30 responden $(51 \%)$ mengalami penurunan fungsi kognitif.

Pada pemeriksaan menggunakan InaMoCA berdasarkan jenis kelamin, perempuan $(97,9 \%)$ cenderung mengalami penurunan fungsi kognitif. Berdasarkan usia didapatkan bahwa usia 60-70 tahun lebih banyak mengalami penurunan fungsi kognitif $(90,3 \%)$. Berdasarkan pekerjaan, didapatkan lansia yang bekerja sebagai nelayan $(100 \%)$ yang mengalami penurunan fungsi kognitif. Berdasarkan tingkat pendidikan terakhir, lansia yang tidak bersekolah (100\%) mengalami penurunan fungsi kognitif. Berdasarkan riwayat penyakit hipertensi, terdapat 23 responden $(41,1 \%)$ mengalami penurunan fungsi kognitif dan berdasarkan riwayat penyakit diabetes melitus terdapat 4 responden $(7,1 \%)$ yang mengalami penurunan fungsi kognitif.

Pemeriksaan TMT-A dan TMT-B menunjukkan bahwa berdasarkan jenis kelamin, perempuan lebih banyak mengalami penurunan fungsi kognitf $(100 \%)$. Berdasarkan usia didapatkan bahwa usia 60-70 tahun mengalami penurunan fungsi kognitif (100\%). Berdasarkan pekerjaan, didapatkan lansia yang tidak bekerja mengalami penurunan fungsi kognitif lebih banyak (100\%). Berdasarkan pendidikan terakhir, yaitu jenjang sekolah dasar cenderung mengalami penurunan fungsi kognitif $(100 \%)$. Berdasarkan riwayat penyakit hipertensi didapatkan 24 orang (100\%) mengalami penurunan fungsi kognitif dan berdasarkan riwayat penyakit diabetes melitus didapatkan 4 orang (100\%) mengalami penurunan fungsi kognitif. 
Hasil pemeriksaan CDT berdasarkan kategori yaitu perempuan lebih banyak mengalami penurunan fungsi kognitif $(52,1 \%)$. Berdasarkan usia terlihat yang mengalami penurunan fungsi kognitif ialah usia $81 \mathrm{ke}$ atas $(75 \%)$. Berdasarkan pekerjaan, didapatkan lansia yang tidak bekerja cenderung mengalami penurunan fungsi kognitif $(54,2 \%)$. Berdasarkan pendidikan terakhir, lansia tidak bersekolah yang mengalami penurunan fungsi kognitif $(80 \%)$. Berdasarkan riwayat penyakit hipertensi, didapatkan 9 orang $(37,5 \%)$ mengalami penurunan fungsi kognitif dan berdasarkan riwayat penyakit diabetes melitus didapatkan 1 orang $(25 \%)$ yang mengalami penurunan fungsi kognitif.

Penurunan fungsi kognitif yang didapatkan dengan komponen terbanyak ialah gangguan visuospasial/eksekutif sebanyak 56 responden $(94,9 \%)$ dan komponen paling sedikit ialah gangguan orientasi sebanyak 23 responden (39\%).

\section{BAHASAN}

Berdasarkan hasil penelitian ini didapatkan responden dengan jenis kelamin perempuan lebih banyak $(81,4 \%)$. Hal ini ditunjang oleh penelitian yang dilakukan oleh Rasyid et al, ${ }^{2}$ Lima et al, ${ }^{5}$ dan Reas et $\mathrm{al}^{6}{ }^{6}$ yang melaporkan bahwa responen perempuan lebih banyak dibandingkan responden laki-laki. Peningkatan jumlah lanjut usia perempuan lebih banyak dibandingkan lanjut usia laki-laki dan perempuan cenderung mengalami penurunan fungsi kognitif yang lebih nyata pada usia yang sudah tua disertai kecepatan psikomotorik yang menurun. ${ }^{2,5,6}$

Pada pemeriksaan Ina-MoCA dan TMT didapatkan usia 60-70 tahun mengalami penurunan fungsi kognitif, sedangkan pada pemeriksaan CDT pada usia $81 \mathrm{ke}$ atas didapatkan penurunan fungsi kognitif. Hal ini sesuai dengan penelitian yang dilakukan oleh Dale et al dan Lipnicki et al. Dikatakan bahwa usia yang lanjut dapat terjadi penurunan fungsi kognitif. ${ }^{6-7}$ Hal ini dikaitkan dengan proses penuaan dan penyakit degeneratif yaitu risiko penyakit kardiovaskuler, meningkatnya peripheral artery disease (PAD) yang akan memengaruhi fungsi vaskuler serebral, perfusi, dan tingkat atrofi otak. ${ }^{8-9}$

Penurunan fungsi kognitif terbanyak pada pemeriksaan Ina-MoCA ialah pekerja nelayan sedangkan pada pemeriksaan TMT-A, TMT-B dan CDT ialah responden yang tidak bekerja. Hal ini sejalan dengan penelitian oleh $\mathrm{Li}$ et $\mathrm{al}^{10}$ yang menyatakan bahwa pekerjaan dapat menjadi prediktor penurunan fungsi kognitif jangka panjang yang lebih baik dari pada pendidikan. Hal ini disebabkan karena pekerjaan lebih erat terlibat dalam jalur yang mengarah pada penurunan fungsi kognitif dengan penyebab yang kompleks serta faktor individu dan lingkungan sehingga risiko terjadi penurunan fungsi kognitif yang bermakna ialah mereka yang bekerja sebagai petani, peternak, nelayan, pedagang, dan ibu rumah tangga dibandingkan mereka yang bekerja menggunakan pikiran yaitu pekerja kantoran.

Penurunan fungsi kognitif terbanyak pada pemeriksaan Ina-MoCA yaitu tidak bersekolah $(100 \%)$ sedangkan pada pemeriksaan TMT-A, TMT-B yaitu sekolah dasar $(100 \%)$ dan pada pemeriksaan CDT yang tidak bersekolah (80\%). Hal ini selaras dengan penelitian yang dilakukan oleh Zahodne et al $^{11}$ yang menyatakan bahwa tingkat pendidikan yang tinggi berhubungan dengan fungsi kognitif yang baik tetapi tingkat pendidikan yang rendah dapat mengalami penurunan fungsi kognitif yang disebabkan karena faktor sosial dan ekonomi. Hal ini ditunjang oleh penelitian dari Toumbaugh $^{12}$ yang menyatakan bahwa terjadi penurunan yang bermakna dari hasil pemeriksaan TMT pada tingkat pendidikan yang rendah.

Berdasarkan riwayat penyakit hipertensi, pada pemeriksaan Ina-MoCA didapatkan 23 orang $(41,1 \%)$, pemeriksaan TMT-A dan TMT-B didapatkan 24 orang (100\%), dan pemeriksaan CDT hanya 9 orang $(37,5 \%)$. Hal ini sesuai dengan penelitian Anto et $\mathrm{al}^{13}$ yang melaporkan bahwa pada pasien hipertensi yang dijadikan sampel sebanyak 57 orang di Rumah Perawatan Karya Kasih Medan didapatkan 
terjadi penurunan fungsi kognitif. Hal ini disebabkan karena terjadi proses penyempitan dan sklerosis dari arteri-arteri kecil di wilayah subkortikal, yang menghasilkan hipoperfusi, kehilangan autoregulasi, penurunan sawar otak, dan akhirnya demielinasi subkortikal putih, mikroinfrak dan gangguan kognitif. Pemeriksaan MRI pada pasien dengan hipertensi kronis sering menunjukkan lesi subkortikal, mikroinfrak, astrogliosis, dilatasi ventrikel, dan akumulasi cairan ekstrasel dibandingkan yang tidak menyandang hipertensi. ${ }^{14}$

Berdasarkan riwayat penyakit diabetes melitus, pada pemeriksaan Ina-MoCA didapatkan 4 orang $(7,1 \%)$, pada pemeriksaan TMT-A dan TMT-B sebanyak 4 orang (100\%), dan pada pemeriksaan CDT didapatkan 1 orang $(25,0 \%)$. Hal ini sesuai dengan penelitian $\mathrm{Li}$ et al $^{15}$ yang melaporkan bahwa pasien DM tipe 2 sering menunjukkan gangguan fungsi kognitif yang bersifat sebagai faktor risiko. Hal ini ditunjang oleh penelitian Cukierman-Yaffe et $\mathrm{al}^{16}$ yang meneliti 300 orang penyandang DM tipe 2 dan mendapatkan adanya hubungan bermakna antara DM dengan gangguan fungsi kognitif. Penyebabnya ialah metabolisme glukosa abnormal dan lesi serebrovaskular di lobus frontal. ${ }^{17}$

Pada responden penelitian yang paling banyak terjadi pada pemeriksaan InaMoCA ialah penurunan fungsi kognitif visuospasial/eksekutif dan yang paling sedikit ialah orientasi. Hal ini sesuai dengan penelitian Glisky ${ }^{18}$ yang menyatakan bahwa semakin bertambah usia maka fungsi eksekutif dapat menurun oleh karena terganggunya korteks prefrontal yang mengontrol di lobus frontal dengan koneksi timbal balik yang luas di daerah kortikal posterior. Seiring bertambahnya usia, visuospasial dapat menurun seperti kemampuan seseorang untuk menggambar yang rumit, tetapi orang yang lebih tua akan memilih menggambar lebih sederhana. ${ }^{19}$

\section{SIMPULAN}

Hasil pemeriksaan Ina-MoCA, TMTA, TMT-B, dan CDT menunjukkan bahwa sebagian besar lansia di Desa Sendangan
Kecamatan Remboken memiliki fungsi kognitif yang terganggu.

Perlu di lakukan pemeriksaan rutin Ina MoCA, TMT, dan CDT atau pemeriksaan fungsi kognititf pada lanjut usia di Desa Sendangan sehingga dapat dilakukan upaya pencegahan. Para lanjut usia perlu mengikuti kegiatan-kegiatan di desa maupun di panti werdha seperti senam pagi, ibadah bersama, atau kegiatan yang dapat mengasah otak seperti kerajinan tangan, dll agar dapat merangsang fungsi kognitif lanjut usia. Penyuluhan tentang fungsi kognitif perlu dilakukan agar masyarakat mengetahui faktor-faktor yang dapat menyebabkan penurunan fungsi kognitif.

\section{Konflik Kepentingan}

Penulis menyatakan tidak terdapat konflik kepentingan dalam studi ini.

\section{DAFTAR PUSTAKA}

1. Analisis lansia di Indonesia. Jakarta: Kementerian Kesehatan RI, 2017.

2. Rasyid IAI, Syafrita Y, Sastri S. Hubungan faktor risiko dengan fungsi kognitif pada lanjut usia Kecamatan Padang Panjang. J Kesehatan Andalas. 2017;6(1):49-54.

3. Centers of Disease Control. Cognitive impairment. U.S Depertment of Health and Human Service, 2011.

4. Susanto RB, Tumewuh R, Mawuntu AH. Gambaran skor MMSE, CDT, TMT A dan TMT B pada lansia di Panti Werdha Tondano. e-Clinic, 2015;3(1):348-52.

5. Lima CP, Amieva H, Letenneur L, Orgogozo JM, Gadda HJ, Dartigues JF. Gender and education impact on brain aging: a general cognitive factor approach. Psychol Aging. 2008;23(3):608-20.

6. Reas ET, Laughlin GA, Bergstrom J, Silverstein DK, Connor EB, McEvoy LK. Effets of sex and education on cognitive change over a 27 -year period in older adults: The Rancho Bernardo Study. Am J Geriatr Psychiatry. 2017;25(8):889-99.

7. Alzheimer's and Dementia. Dementia. Journal Alzheime's Association Report. 2019.

8. Izzah A. Hubungan aktivitas fisik dengan 
fungsi kognitif lansia pada lansia usia 60-69 tahun di Kelurahan Purwantoro Kecamatan Belimbing Kota Malang. J Fak Kedokt Muhammadiyah Malang. 2014;10(2):88-93.

9. Lipnicki DM, Sachdev PS, Crawford J, Reppermund S, Kochan NA, Trollor $\mathrm{JN}$, et al. Risk factors for late-life cognitive decline and variation with age and sex in the sydney memory and ageing study. PLOS Med. 2013;8(6):e65841.

10. Li CY, Wu SY, Sung FC. Lifetime principal occupation and risk of cognitive impairment among the elderly. Ind Health. 2002;40(1):7-13.

11. Zahodhe L, Stern Y, Manly JJ. Differing effects of education on cognitive decline in diverse elders with low versus high educational attainment. Neuropsychology. 2015;29(4):649-57.

12. Tombaugh TM. Trail making test A and B: normative data stratified by age and education. Arch Clin Neuropsychol. 2004;19:203-14.

13. Anto EJ, Siagian LO, Siahaan JM, Sititonga HA, Nugraha SE. The relationship between hypertension and cognitive function impairment in elderly. Open Access Maed J Med Sci. 2019;7(9):1440-5.
14. Athika N, Maja J, Mawuntu AHP. Gambaran Skor MMSE dan MoCA-INA pada pasien cedera kepala ringan dan sedang di RSUP Prof. Dr. R. D. Kandou Manado. e-CliniC. 2016;4(1):1-8.

15. Li W, Sun L, Li G, Xiao S. Prevalence, influence factors and cognitive characteristics of mild cognitive impair ment in type 2 diabetes mellitus. Front Aging Neurosci. 2019;11(180):1-7.

16. Yaffe TC, Gerstein H, Villiamson JD, Lazar RM, Lovato L, Miller ME, et al. Relationship between baseline glycemic control and cognitive function in individuals with type 2 diabetes and other cardiovascular risk factors. Diabet Care. 2009;32(2):221-6.

17. Kawamura T, Umemura T, Hotta N. Cognitive impairment in diabetic patients: Can diabetic control prevent cognitive decline? J Diabetes Investig. 2012;3(5):413-23.

18. Glisky E. Changes in cognitive function in human aging. In: Riddle $\mathrm{D}$, editor. Brain Aging: Models, Methods, and Mechanisms. Boca Raton: Taylor and Francis, 2007.

19. Murmun DL. The impact of aging on cognition. Semin Hear. 2015;36(3): 111-21. 